8-23-2021

\title{
Impact of community-based girl groups
}

Miriam Temin

Population Council

Craig Heck

Follow this and additional works at: https://knowledgecommons.popcouncil.org/departments_sbsr-pgy How does access to this work benefit you? Let us know!

\section{Recommended Citation}

Temin, Miriam and Craig Heck. 2021. "Impact of community-based girl groups," GIRL Center Research Brief no. 6. New York: Population Council. 


\title{
GIRL然Center
}

FOR INNOVATION, RESEARCH, AND LEARNING
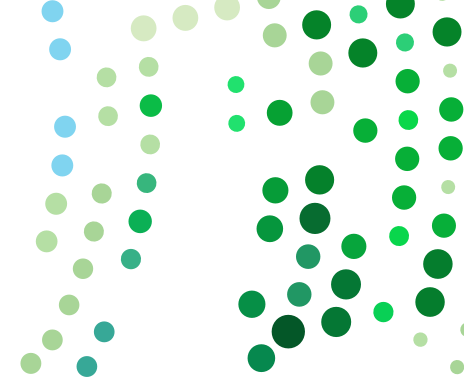

\section{GIRL Center Research Brief}

No. 6 August 2021

\section{IMPACT OF COMMUNITY-BASED GIRL GROUPS MIRIAM TEMIN AND CRAIG HECK}

\begin{abstract}
AT A GLANCE
Programs increasingly use community-based girl groups (CBGGs) to address risks and empower adolescent girls, but evidence on their impact is not always accessible to decision makers. A closer look at 30 CBGG programs in low- and middle-income countries found that CBGGs had the greatest reported success in improving health and gender attitudes and beliefs, while their effect on health behavior and status is mixed. Program implementers should consider CBGGs as a way to facilitate girls' empowerment, with complementary measures to engage community members and to promote enabling environments for greater program impact. Increased interest and investment in CBGGs should be supported by greater investment in further research to bolster the evidence base.
\end{abstract}

\section{BACKGROUND}

Attention to adolescents, especially girls, has increased globally yet many girls still lack access to essential services and basic human rights. Adolescent girls remain at high risk of outcomes that inhibit long term growth and development - like child marriage, early pregnancy, and HIV infection. At the same time, girls often miss the benefits of social programs due to social isolation and marginalization.

To address the risks and needs of adolescent girls who are more difficult to reach through formal avenues such as schools and health services, more programs across regions are utilizing community-based girl groups.

With the increased use of CBGGs, evaluations including randomized controlled trials (RCTs) and quasi-experimental studies - continue to expand the evidence base on their impact. Nevertheless,

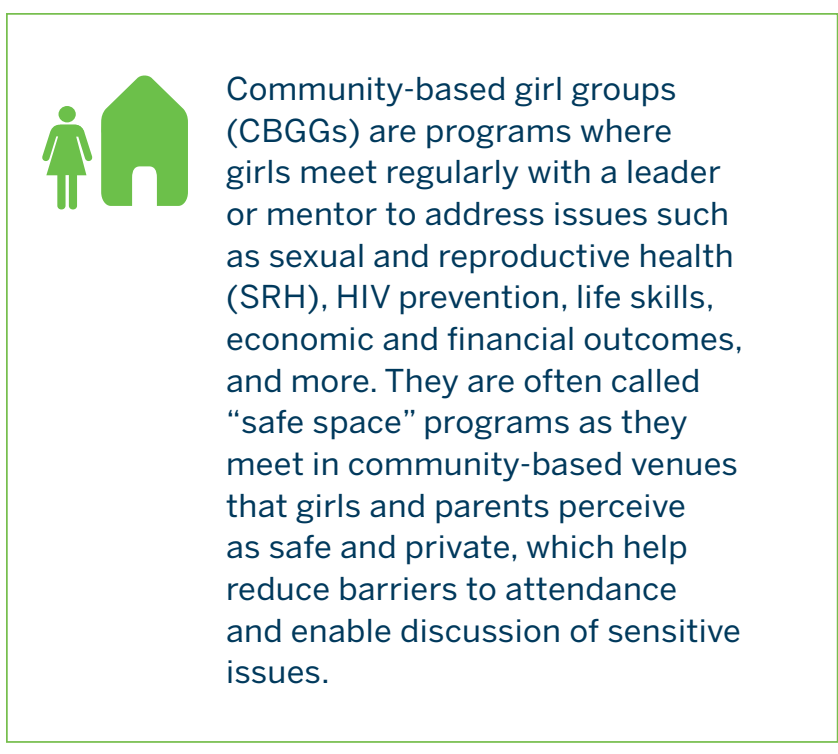

the existing evidence is not always accessible to decision makers, in part due to limited efforts to synthesize this growing body of evidence. To fill this gap, we conducted a literature review and took a closer look at 30 CBGG programs in lowand middle-income countries (LMICs). ${ }^{1}$ 


\section{METHODS}

The literature review examined evidence on CBGGs in LMICs, centered around four components: program design (group size, meeting frequency, session duration, and program duration), program effects evaluated, program effects reported, and the types of studies that generated results (RCTs versus quasi-experimental studies).

To be included in the review, the program had to operate or conclude between 2000 and 2017, and include:

- A group of 10- to 19-year-old girls who met twice or more over the respective program duration

- A female mentor who received dedicated training for the role

- A meeting venue located in a community setting (rather than a formal institution like schools during school hours or hospitals)

To identify literature on CBGG programs that met the inclusion criteria listed above, we searched existing reviews of evidence on adolescent interventions, research and journal databases, as well as websites of program implementers for adolescent girls in LMICs. From these studies, we extracted data on program design and effects, and compared results across programs.

To assess a wide range of program effects, we grouped programs into 8 outcome categories based on their goals: health beliefs and attitudes; gender beliefs and attitudes; education-related outcomes; psychosocial outcomes; health and gender knowledge and awareness; economic and financial outcomes; health-related behavior; and health status. Based on these categories, we reviewed beneficial program effects, defined as statistically significant changes in the direction the program expected. In order to compare evidence from a wide range of evaluations, we considered effects relative to the programs' stated aims, rather than the absolute size of the effects.

\section{KEY FINDINGS}

CBGGs showed most success in improving health and gender attitudes and beliefs. In terms of the proportion of measured program effects, $91 \%$ were beneficial for health attitudes and beliefs, and $72 \%$ for gender attitudes and beliefs (Figure 2). These programs focused on attitudes and beliefs about threats to girls' growth and development (e.g. early pregnancy, female genital mutilation/cutting) and addressed practices like child marriage and gender-based violence. Other outcome areas were also successful, though at a lower rate. $65 \%$ of the program effects measured on education (e.g. numeracy and school enrollment) were beneficial. Closely following these were: psychosocial outcomes like

\section{A CLOSER LOOK AT CBGGS REVIEWED}

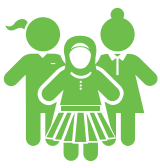

Around one-third of programs adapted its design for different girl segments (for example by age or marital status), recognizing that differences among adolescent girls can mean varied participation and program effects.

Younger girls attended more frequently than older girls, and unmarried girls attended more frequently than married girls, whose responsibilities and social expectations differ.

Most programs included content on life skills ${ }^{2}$, often combining life skills with other activities related to economic and financial outcomes - like income generation skills, financial literacy training, and access to microsavings or cash transfers (Figure 1). 
FIGURE 1. TYPES OF GIRL-CENTERED CONTENT IN THE 30 CBGG PROGRAMS REVIEWED (NUMBER OF PROGRAMS)

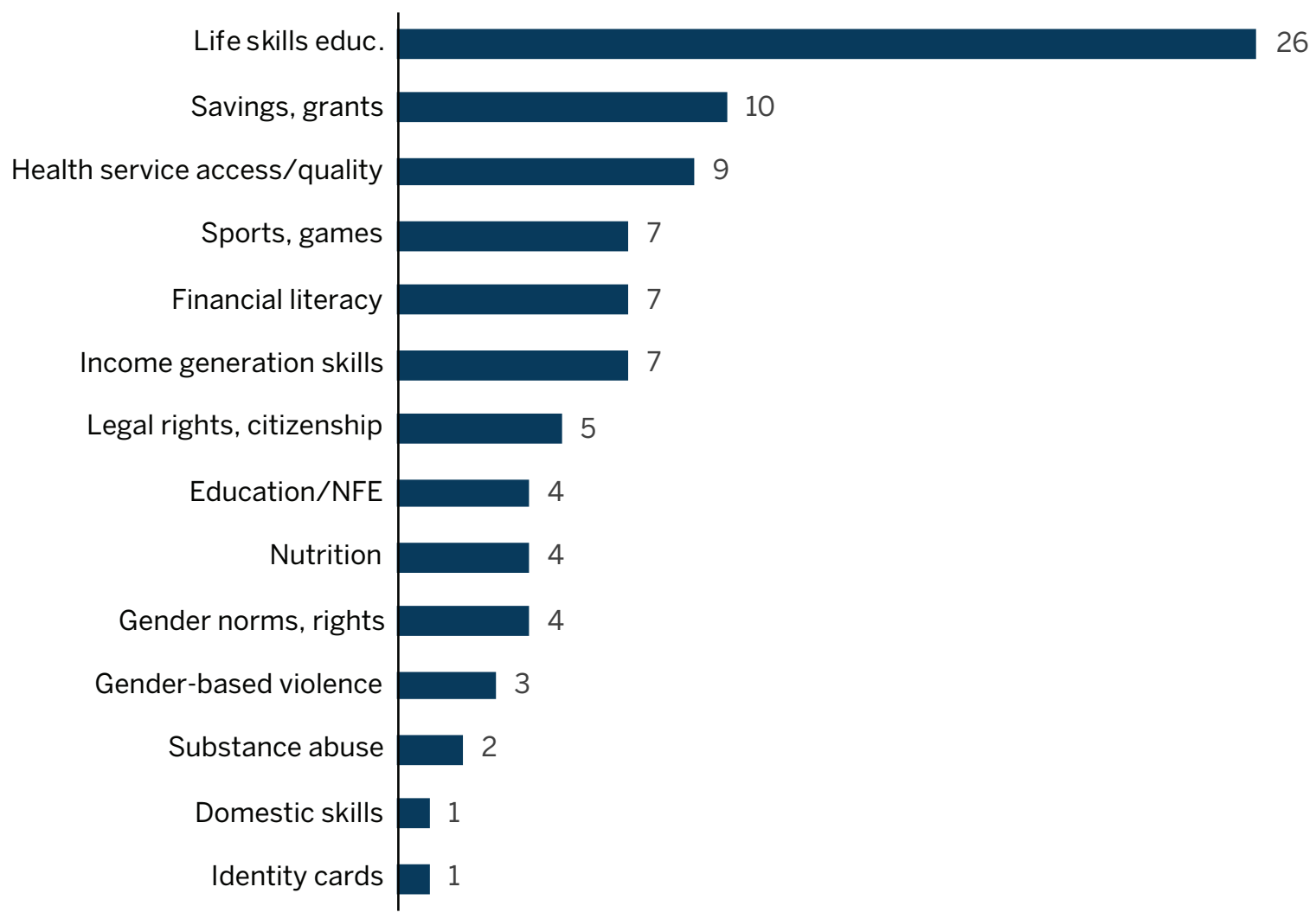

self-efficacy and social support (64\%), knowledge and awareness on health and gender issues (62\%) and economic and financial elements like employment and savings (60\%).

Despite these reported program effects on factors that can indirectly contribute to improved health behavior and health status, evidence on whether the programs actually translated to better health behavior and health status is mixed. Only $38 \%$ of reported program effects on health behavior were beneficial, with effects on secondary abstinence and menstrual hygiene management relatively stronger than health utilization and child marriage. Fewer significant effects were reported for girls' number of sex partners, transactional sex, condom use, sexual debut, and contraceptive use. Similarly, only $26 \%$ of health status effects reported were beneficial, including HIV \& herpes simplex virus (HSV-2) incidence, experience of violence, mental health status.

On their own, CBGGs have more potential to facilitate internal change for girls than interpersonal, organization, and communitylevel impact. Findings suggest that the main benefits of CBGG programs reflect changes that are within girls-for example, attitudes toward child marriage, demand for health services, self-esteem, and literacy. Program effects are weaker on outcomes that rely on factors external to girls-such as condom use, HIV testing, child marriage, and health service utilization - though more longer-term evaluation would be needed to draw robust conclusions about these outcomes. 
FIGURE 2. DISTRIBUTION OF CBGG PROGRAM EFFECTS BY EVALUATION TYPE AND OUTCOME AREA (\% OF MEASURED PROGRAM EFFECTS)

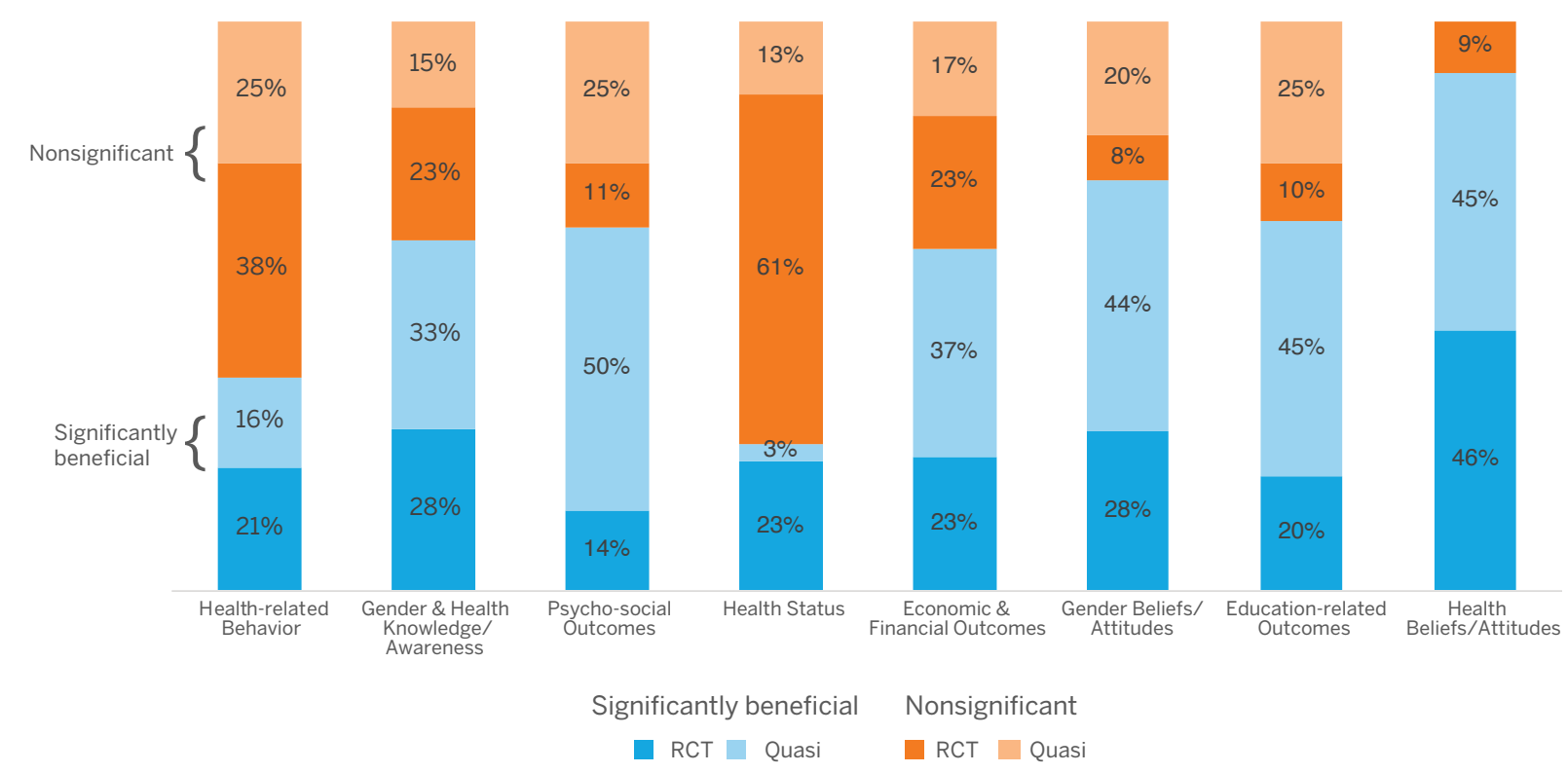

RCT: Randomized controlled trials, Quasi: Quasi-experimental studies

\section{RECOMMENDATIONS}

Program implementers should consider CBGGs as a way to facilitate girls' empowerment, which can contribute to improving their health and wellbeing in the right environment, particularly for girls who are harder to reach. Female mentor-led girl groups show potential as a way to: build girls' economic and psychosocial assets; improve their attitudes, beliefs, knowledge, and awareness on health and gender; and enhance education-related outcomes.

For greater impact, measures to engage community members and to promote enabling environments should complement CBGGs. CBGGs do not operate in a vacuum. Programs need to take into account the critical role that girls' social and structural environments play in girls' abilities to translate changes in attitudes and knowledge into behavior. For instance, complementing CBGGs focused on health with enhanced access to and quality of health services may enhance program impact on girls' health behavior and status. It will also be important to measure community-level changes that may contribute to the success of CBGGs in promoting sustainable improvements for adolescent girls, particularly in terms of behavior change.

Increased interest and investment in CBGGs should be supported by greater investment in further research to bolster the evidence base. Further research would allow for more rigorous comparisons across various program designs and outcome areas. More evidence that disaggregates results to reflect differences among adolescents and to assess the success of programs in reaching marginalized girls - who face the highest riskswould be helpful. Stronger evidence of impact on outcomes like mental health, nutrition, and child marriage would be a particularly valuable contribution. Furthermore, evidence on the scalability of CBGGs, such as a minimum package of elements required for effective programs, would be informative for program implementers and policy makers to translate evidence into action. 
NOTES

1 Temin, Miriam and Craig Heck. 2020. "Close to home: Evidence on the impact of community-based girl groups," Global Health: Science and Practice 8(2): 300-324.

2 As defined by UNICEF, life skills education seeks to equip young people to negotiate and mediate challenges and risks in their lives, and to enable productive participation in society.
The Girl Innovation, Research, and Learning (GIRL) Center is a global research center that generates, synthesizes, and translates evidence to transform the lives of adolescent girls. Through rigorous research about what works - and what doesn't - we can better direct limited resources to support evidencebased solutions that improve girls' lives.

popcouncil.org/girlcenter

Recommended citation: Temin, M., C. Heck. 2021. "Impact of Community-based Girl Groups." GIRL Center Research Brief No. 6. New York: Population Council. 